\title{
(2) OPEN ACCESS \\ Hospital care for the dying patient with cancer: does an advance care planning invitation influence bereaved relatives' experiences? A two country survey
}

\author{
Nina Elisabeth Hjorth (D) ,,2 Karl Ove Hufthammer (D) , \\ Katrin Sigurdardottir (D) ,2,4 Vilma Adriana Tripodoro (D) , 5,6 \\ Gabriel Goldraij, ${ }^{7}$ Anne Kvikstad, ${ }^{8,9}$ Dagny Faksvåg Haugen (D) ,,4 on \\ behalf of the ERANet-LAC CODE project group
}

\begin{abstract}
- Additional supplemental material is published online only. To view, please visit the journal online (http://dx.doi. org/10.1136/bmjspcare-2021 003116).
\end{abstract}

For numbered affiliations see end of article.

\section{Correspondence to}

Dr Nina Elisabeth Hjorth, Faculty of Medicine, Department of Clinical Medicine K1, University of Bergen, Bergen, Norway; nina.elisabeth.hjorth@helsebergen.no

Received 13 April 2021 Accepted 21 October 2021

\section{Check for updates}

(c) Author(s) (or their employer(s)) 2021. Re-use permitted under CC BY-NC. No commercial re-use. See rights and permissions. Published by BMJ.

\footnotetext{
To cite: Hjorth $\mathrm{NE}$,

Hufthammer $\mathrm{KO}$,

Sigurdardottir K, et al. BMJ

Supportive \& Palliative

Care Epub ahead of

print: [please include Day

Month Year]. doi:10.1136/

bmjspcare-2021-003116
}

\section{ABSTRACT}

Objectives Advance care planning (ACP) is not systematically performed in Argentina or Norway. We used the post-bereavement survey of the ERANet-LAC International Care Of the Dying Evaluation (CODE) project (2017-2020) to examine the proportion of relatives who were offered an ACP conversation, the proportion of those not offered it who would have wanted it and whether the outcomes differed between those offered a conversation and those not.

Methods Relatives after cancer deaths in hospitals answered the CODE questionnaire 68 weeks post bereavement, by post (Norway) or interview (Argentina). Two additional questions asked if the relative and patient had been invited to a conversation about wishes for the patient's remaining lifetime, and, if not invited, whether they would have wanted such a conversation. The data were analysed using mixed-effects ordinal regression models.

Results 276 participants (Argentina 98 and Norway 178 ) responded (56\% spouses, $31 \%$ children, $68 \%$ women, age $18-80+$ ). Fiftysix per cent had been invited, and they had significantly more positive perceptions about care and support than those not invited. Sixty-eight per cent of the participants not invited would have wanted an invitation, and they had less favourable perceptions about the care, especially concerning emotional and spiritual support.

Conclusions Relatives who had been invited to a conversation about wishes for the patient's remaining lifetime had more positive perceptions about patient care and support for the relatives in the patient's final days of life. A majority of the relatives who had not been invited to an ACP conversation would have wanted it.

\section{Key messages}

What was already known?

- Systematic implementation of advance care planning (ACP) programmes increases in-advance end-of-life discussions.

- Questions about ACP are not routinely included in post-bereavement surveys.

What are the new findings?

- Relatives who had been invited to an ACP conversation had more positive perceptions about support and patient care in the patient's final days.

- Relatives who had not been invited to an ACP conversation, but would have wanted it, had the least favourable perceptions about support and care.

What is their significance?

- Clinical

- Offering ACP and goals-of-care discussions may positively influence relatives' experiences of end-of-life care.

- Research

- Post-bereavement surveys may be used to evaluate the effect of ACP.

\section{INTRODUCTION}

Good care for the patient with cancer requires knowledge about the expected disease trajectory, the broad spectrum of treatments and the patient's perspectives on treatment and care. ${ }^{12}$ The patient's perspective is obtained through shared decision-making, with healthcare personnel and the patient working together to make achievable plans for future treatment and care. ${ }^{3-5}$ This 
approach is crucial when planning end-of-life (EoL) care, commonly described as advance care planning (ACP). ACP is defined as a process of conversations which 'enables individuals to define goals and preferences for future medical treatment and care, to discuss these goals and preferences with family and healthcare providers and to record and review these preferences if appropriate'. ${ }^{6}$ ACP addresses individuals' concerns across the physical, psychological, social and spiritual domains. ${ }^{6}$ Although ACP is used worldwide, the timing and degree of offering such conversations vary, which probably influences patient autonomy and the quality of EoL care. $^{78}$

Argentina and Norway are two countries still without national ACP programmes informing and offering the population to plan ahead in case of serious illness scenarios. A systematic ACP approach for patients diagnosed with serious or advanced disease is also nonexisting. Thus, $\mathrm{ACP}$ as a concept is not generally known in the population nor among healthcare personnel, even though Argentina has a law that allows people to formulate advance directives. Standardised and easily retrievable ACP documentation about patients' wishes and values is not in use in hospital care. Consequently, ACP conversations are not offered on a regular basis, although there is a growing interest in shared decisionmaking as part of goals-of-care discussions due to an increasing claim for patient autonomy. This situation allows us to study how different approaches to communication about EoL issues influence the quality of care for dying patients.

Norway had 11000 cancer deaths in 2018; 34\% took place in hospitals. ${ }^{9}$ In Argentina, 61000 individuals died from cancer in 2018. Figures on the proportion that died in hospitals are not available, but almost $70 \%$ of all deaths in this country take place in 'healthcare institutions'. ${ }^{10}$ The hospital setting thus lends itself to research aiming at improving the quality of care for dying patients with cancer.

Data presented in this paper were collected as part of an international post-bereavement survey after cancer deaths in hospitals in seven European and South-American countries. ${ }^{11}$ The survey used the international version of the CODE (Care Of the Dying Evaluation) questionnaire. ${ }^{12} 13$ In Argentina and Norway, two additional questions about being offered an ACP conversation in advanced disease were included in the survey, with the aim to answer the following research questions:

1. What proportion of the bereaved relatives were offered an ACP conversation?

2. What proportion of the relatives that were not offered an ACP conversation would have wanted it?

3. Were there differences in outcomes between the relatives offered an ACP conversation and those not, with special reference to communication issues and emotional and spiritual support?
4. Do the answers to the above questions differ between participants from Argentina and Norway?

\section{METHODS}

\section{Study design}

This substudy was part of CODE International Survey, conducted as part of the ERANet-LAC CODE project 2017-2020: 'International Care Of the Dying Evaluation (CODE): Quality of care for dying cancer patients as perceived by bereaved relatives'. ${ }^{11} 14$ The survey employed the international version of the validated CODE questionnaire, i-CODE. ${ }^{12} 13$ This questionnaire focuses on the two final days of life and the immediate bereavement period. It has the following seven sections: (A) The care received from the nurses and doctors, (B) the control of pain and other symptoms, (C) communication with the healthcare team, (D) the emotional and spiritual support provided by the healthcare team, (E) the circumstances surrounding his/her death, $(F)$ overall impressions and $(G)$ information about you and your relative or friend. ${ }^{13}$ In Norway and Argentina, two questions were added to section (F) (Q32a) 'When it became clear that she/he was seriously ill and had limited time left to live, did the healthcare team (nurse or doctor) invite you and him/her to a conversation about your wishes for his/ her remaining life time?' (response options: Yes/No/ Don't know); (Q32b) 'Would you have wanted this type of conversation?' (response options: $\mathrm{Yes} / \mathrm{No} / \mathrm{Not}$ applicable, we had this type of conversation). In the following, we use the term ACP conversation for the conversations addressed in these two questions.

\section{Study setting}

Participants were recruited to this post-bereavement survey from 22 hospitals in seven countries in Europe and South America from 15 August 2017 to 15 September 2018. In Norway, participants were recruited from medical, surgical and oncology wards and palliative care inpatient units at three university hospitals and four acute care hospitals (all public). In Argentina, participants were recruited from medical, surgical and oncology wards and intensive care units at three university hospitals (two public and one private).

\section{Participants}

Adult relatives of adult patients with cancer dying an expected death in one of the selected hospitals in Norway and Argentina were eligible for inclusion. Their relation with the patient had to be documented in the patient's hospital record. Written informed consent was mandatory for participation. Patients had to have been hospitalised for at least three calendar days, with the relative present at least some of the time during the last 2 days. A patient with cancer was defined as any patient with a solid cancer or haematological malignancy, but not necessarily dying from the malignant disease. The attending physician was 
consulted in case of doubt about whether the death was expected or not. If the physician was not available, any death of a patient with cancer without resuscitation being attempted was accepted. Participants were excluded if the patient had a sudden and unexpected death or if the relative was unable to complete the questionnaire due to impaired cognitive functioning or lack of language abilities.

\section{Procedure}

Recruitment

Upon the death of a patient, local project coordinators among the ward staff (Norway) or local study teams (Argentina) identified potential participants by screening the case notes (Norway) or lists of deceased patients during the last month (Argentina). In Norway, information was given in verbal and written form prior to the relative leaving the hospital. If missed, a leaflet was sent by surface mail. In Argentina, eligible relatives were approached by telephone; in some cases, relatives were approached by the specialist palliative care team before leaving the hospital.

Data collection

The questionnaire was presented to the participants 6-8 weeks after bereavement. In Argentina, participants were either interviewed by telephone $(50 \%)$ or face-to-face (37\%) by social workers or physicians with relevant research experience, or responded by email $(13 \%)$. In Norway, data collection was only by postal survey, with one postal reminder to non-respondents after 4 weeks.

In addition to the questionnaire data, the following information was collected from the patients' medical records by ward staff: primary site of the cancer, length of hospital stay, type of ward (place of death), contact with a specialist palliative care team and use of an individualised care plan for care of the dying. The data were stored on a protected research server.

\section{Primary outcomes}

The two primary outcomes of CODE International Survey were the participants' perception of how much of the time the patient was treated with respect and dignity in the last 2 days of life by doctors and by nurses (Q30, two questions), and whether the participant was adequately supported during the same period (Q31).

\section{Patient and public involvement}

The validated CODE questionnaire was developed according to acknowledged questionnaire development methodology, with input from lay persons and representatives from the target group at every step. ${ }^{12}$ The translated versions in Norway and Argentina were piloted and pretested with volunteers and bereaved relatives before being used in the survey. ${ }^{13}$

\section{Data analysis}

We present demographic data as counts and percentages. To examine differences in outcomes (eg, quality of communication, or emotional or spiritual support) between the relatives offered an ACP conversation and those not, we fitted separate mixed-effects ordinal regression models with questions Q16, Q17, Q20Q24, Q31 and the two Q30 questions as response variables (table 1). The same type of model was used to compare, for those not offered such a conversation, the outcomes between those who would have wanted to be offered a conversation and those not.

The response variables had different response options, either ordinal (eg, for the level of emotional support given (Q20), 'poor', 'fair', 'good' or 'excellent') or binary ('no' or 'yes'). For binary variables, the ordinal model is reduced to a logistic model. The explanatory variables were Q32a and Q32b (separate models). To take into account any general differences in outcomes between hospitals, hospital was included as a random intercept. The output from each model is an OR. A common OR is estimated over all possible cut-offs of the response variable, which was coded such that an OR $>1$ indicates that a 'yes' response to Q32a/Q32b was associated with a more positive response (eg, better communication, or better spiritual support).

To examine country differences, we created extended versions of the above models by adding country and the interaction between country and each explanatory variable. The original and extended models were compared using likelihood ratio tests. Results stratified by country are presented in the supplemental material published online only.

Before analysis, the data were recoded to remove any internal inconsistencies (eg, people responding 'yes' to Q32a but not 'not applicable' to Q32b). When a patient had missing data on a question-either a lack of response or a 'don't know' response-they were excluded from the analyses that used that question (but included in other analyses). We also report the number of responses each analysis is based on.

The data were stored in Microsoft Excel 2016 spreadsheet files, and all recoding and statistical analyses were done using $\mathrm{R}$ V.4.0.2. ${ }^{15}$ The regression models were fitted using the $\mathrm{R}$ package 'ordinal' V.2019.12-10. ${ }^{16}$

\section{RESULTS}

\section{Participants and patients}

The survey included 194 participants in Norway and 105 in Argentina (response rate 58\% in both countries). The majority of participants were women (Argentina 68\% and Norway 70\%), with 50-59 (Argentina) and 60-69 (Norway) years as the median age groups. In the following, we analyse only the 276 participants (see flowchart, figure 1) who responded 'yes' or 'no' to the question $(\mathrm{Q} 32 \mathrm{a})$ about whether they were invited to an ACP conversation. Table 2 gives an overview of characteristics of both participants and patients. 


\begin{tabular}{|c|c|c|}
\hline Item & Question/statement text & Response options \\
\hline \multicolumn{3}{|c|}{ Response variables } \\
\hline Q16 & $\begin{array}{l}\text { During the last } 2 \text { days, how involved were you with the decisions about his/her care } \\
\text { and treatment? }\end{array}$ & Very involved; Fairly involved; Not involved \\
\hline Q17 & $\begin{array}{l}\text { Did any of the healthcare team discuss with you whether giving fluids through a } \\
\text { 'drip' would be appropriate in the last } 2 \text { days of life? }\end{array}$ & Yes; No; Don't know \\
\hline Q20 & $\begin{array}{l}\text { How would you assess the overall level of emotional support given to you by the } \\
\text { healthcare team? }\end{array}$ & Excellent; Good; Fair; Poor \\
\hline Q21 & Overall, his/her religious or spiritual needs were met by the healthcare team. & $\begin{array}{l}\text { Strongly agree; Agree; Neither agree nor disagree; } \\
\text { Disagree; Strongly disagree }\end{array}$ \\
\hline Q22 & Overall, my religious or spiritual needs were met by the healthcare team. & $\begin{array}{l}\text { Strongly agree; Agree; Neither agree nor disagree; } \\
\text { Disagree; Strongly disagree }\end{array}$ \\
\hline Q23 & Before she/he died, were you told she/he was likely to die soon? & Yes; No \\
\hline Q24 & $\begin{array}{l}\text { Did a member of the healthcare team talk to you about what to expect when she/he } \\
\text { was dying (eg, symptoms that may arise)? }\end{array}$ & Yes; No \\
\hline Q30 & $\begin{array}{l}\text { How much of the time was she/he treated with respect and dignity in the last } 2 \text { days } \\
\text { of life? (doctors/nurses) }\end{array}$ & $\begin{array}{l}\text { Always; Most of the time; Some of the time; Never; } \\
\text { Don't know }\end{array}$ \\
\hline Q31 & $\begin{array}{l}\text { Overall, in your opinion, were you adequately supported during his/her last } 2 \text { days } \\
\text { of life? }\end{array}$ & Yes; No \\
\hline \multicolumn{3}{|c|}{ Explanatory variables } \\
\hline Q32a & $\begin{array}{l}\text { When it became clear that she/he was seriously ill and had limited time left to live, } \\
\text { did the healthcare team (nurse or doctor) invite you and him/her to a conversation } \\
\text { about your wishes for his/her remaining life time? }\end{array}$ & Yes; No; Don't know \\
\hline Q32b & Would you have wanted this type of conversation? & $\begin{array}{l}\text { Yes; No; Not applicable, we had this type of } \\
\text { conversation }\end{array}$ \\
\hline
\end{tabular}

\section{ACP conversations}

As shown in figure 1, 56\% of the patients and participants had been invited to an ACP conversation (Argentina 58\% and Norway 54\%). In the group not invited, $68 \%$ would have wanted this type of conversation, the same proportion in both countries.

\section{Perceptions about care and support}

We wanted to explore whether having been offered an ACP conversation was related to the participants' perceptions about the care given. The main outcomes are shown in figures 2 and 3. The participants who had been invited to an ACP conversation perceived that the dying patient had been treated with respect and dignity more of the time, by both doctors and nurses (figure 2). In the group that had not been offered an ACP conversation, the participants who would have wanted to be offered one, perceived that the dying patient had been treated with respect and dignity less of the time, by both doctors and nurses (figure 3).

Results of the ordinal regression models examining differences in main outcomes, communication and support between the participants offered an ACP conversation and those not, are presented in table 3 , left panel. Here, an OR $>1$ indicates that the participants who had been invited to an ACP conversation gave more positive responses. The participants perceived that they were more involved in care decisions, received better emotional and spiritual support, and were better informed about what to expect in the dying phase. Overall, they felt better supported in the patient's last days. They also perceived that the patient received better spiritual support and was more often treated with dignity and respect by the doctors.

Differences between countries were only found for Q23 and Q30 for nurses, for which the p values for country differences (including an interaction effect) were 0.002 and 0.004 , respectively. All other $p$ values were $>0.10$. Detailed results are shown stratified by country in online supplemental table A1, available in the supplemental material published online only. In Argentina, 39\% of those not invited to an ACP conversation had also not been informed about the patient's impending death. Of those who had been invited, the corresponding proportion was 7\%. In Norway, the corresponding proportions were $11 \%$ for both groups. The OR for the Q30 item for nurses was similar in the two countries, but the item was answered less favourably in Argentina than in Norway. This was anticipated, as there is a huge lack of qualified nurses in Argentina. ${ }^{17}$

The results for participants who had not been offered an ACP conversation are presented in table 3, right panel. The OR values $<1$ indicate that the participants who would have wanted a conversation rated the communication and emotional and spiritual support less favourably than the ones who had not wanted such a conversation. There was, however, no difference in their perception of their degree of involvement in care decisions. Again, the only country differences were 


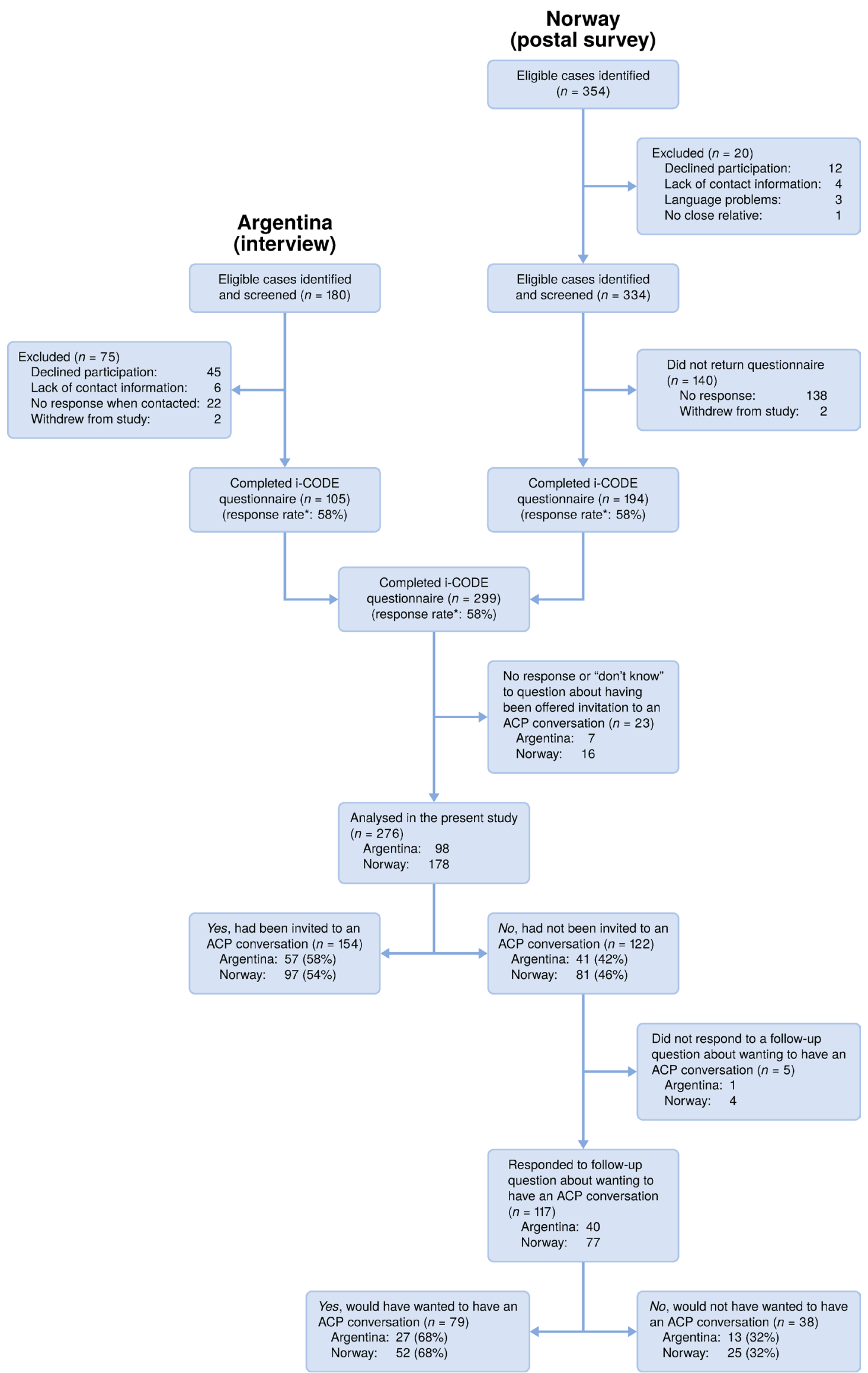

Figure 1 Flowchart showing participants and responses. *Based on the number of eligible cases identified and screened. ACP, advance care planning; i-CODE, international version of the validated Care Of the Dying Evaluation questionnaire. 
Table 2 Characteristics of the deceased patients and study participants

\begin{tabular}{|c|c|c|c|c|c|c|c|c|}
\hline & \multicolumn{4}{|c|}{ Deceased patients } & \multicolumn{4}{|c|}{ Participants (relatives) } \\
\hline & \multicolumn{2}{|c|}{ Argentina } & \multicolumn{2}{|c|}{ Norway } & \multicolumn{2}{|c|}{ Argentina } & \multicolumn{2}{|c|}{ Norway } \\
\hline & No. & Prop. & No. & Prop. & No. & Prop. & No. & Prop \\
\hline \multicolumn{9}{|l|}{ Gender } \\
\hline Male & 55 & $56 \%$ & 114 & $64 \%$ & 32 & $33 \%$ & 51 & $29 \%$ \\
\hline Female & 43 & $44 \%$ & 64 & $36 \%$ & 65 & $66 \%$ & 124 & $70 \%$ \\
\hline (Missing) & 0 & $0 \%$ & 0 & $0 \%$ & 1 & $1 \%$ & 3 & $2 \%$ \\
\hline \multicolumn{9}{|l|}{ Age } \\
\hline $18-29$ & 0 & $0 \%$ & 1 & $1 \%$ & & & 1 & $1 \%$ \\
\hline $30-39$ & 4 & $4 \%$ & 4 & $2 \%$ & 16 & $16 \%$ & 7 & $4 \%$ \\
\hline $40-49$ & 7 & $7 \%$ & 10 & $6 \%$ & 17 & $17 \%$ & 19 & $11 \%$ \\
\hline $50-59$ & 9 & $9 \%$ & 27 & $15 \%$ & 20 & $20 \%$ & 39 & $22 \%$ \\
\hline $60-69$ & 34 & $35 \%$ & 49 & $28 \%$ & 18 & $18 \%$ & 40 & $22 \%$ \\
\hline $70-79$ & 23 & $23 \%$ & 56 & $31 \%$ & 14 & $14 \%$ & 24 & $13 \%$ \\
\hline $80-89$ & 18 & $18 \%$ & 27 & $15 \%$ & 4 & $4 \%$ & 6 & $3 \%$ \\
\hline $90+$ & 3 & $3 \%$ & 4 & $2 \%$ & 9 & $9 \%$ & 42 & $24 \%$ \\
\hline \multicolumn{9}{|l|}{ Religious affiliation } \\
\hline None & 13 & $13 \%$ & 38 & $21 \%$ & 15 & $15 \%$ & 33 & $19 \%$ \\
\hline Christian (all denominations) & 83 & $85 \%$ & 124 & $70 \%$ & 76 & $78 \%$ & 132 & $74 \%$ \\
\hline Any other religion & 2 & $2 \%$ & 11 & $7 \%$ & 7 & $7 \%$ & 10 & $6 \%$ \\
\hline (Missing) & 0 & $0 \%$ & 5 & $3 \%$ & $0 \%$ & $0 \%$ & 3 & $2 \%$ \\
\hline \multicolumn{9}{|l|}{ Participant was the patient's } \\
\hline Spouse/partner & - & - & - & - & 45 & $46 \%$ & 111 & $62 \%$ \\
\hline Son/daughter & - & - & - & - & 35 & $36 \%$ & 50 & $28 \%$ \\
\hline Brother/sister & - & - & - & - & 10 & $10 \%$ & 8 & $4 \%$ \\
\hline Son-in-law/daughter-in-law & - & - & - & - & 1 & $1 \%$ & 1 & $1 \%$ \\
\hline Parent & - & - & - & - & 2 & $2 \%$ & 4 & $2 \%$ \\
\hline Friend & - & - & - & - & 2 & $2 \%$ & 2 & $1 \%$ \\
\hline Other & - & - & - & - & 3 & $3 \%$ & 1 & $1 \%$ \\
\hline (Missing) & - & - & - & - & 0 & $0 \%$ & 1 & $1 \%$ \\
\hline \multicolumn{9}{|c|}{ Cancer diagnosis (possible with more than one) } \\
\hline Gastrointestinal, incl. pancreatic & 55 & $56 \%$ & 63 & $35 \%$ & - & - & - & - \\
\hline Respiratory organs & 14 & $14 \%$ & 40 & $22 \%$ & - & - & - & - \\
\hline Urological, incl. prostate & 8 & $8 \%$ & 23 & $13 \%$ & - & - & - & - \\
\hline Leukaemia/lymphoma & 8 & $8 \%$ & 14 & $8 \%$ & - & - & - & - \\
\hline Breast & 2 & $2 \%$ & 9 & $5 \%$ & - & - & - & - \\
\hline Brain & 3 & $3 \%$ & 4 & $2 \%$ & - & - & - & - \\
\hline Gynaecological & 1 & $1 \%$ & 2 & $1 \%$ & - & - & - & - \\
\hline Other & 8 & $8 \%$ & 30 & $17 \%$ & - & - & - & - \\
\hline \multicolumn{9}{|l|}{ Type of ward where the patient died } \\
\hline Medical or surgical ward & 73 & $74 \%$ & 65 & $37 \%$ & - & - & - & - \\
\hline Palliative care unit & 0 & $0 \%$ & 78 & $44 \%$ & - & - & - & - \\
\hline Oncology ward & 23 & $23 \%$ & 33 & $19 \%$ & - & - & - & - \\
\hline Intensive care unit & 1 & $1 \%$ & 0 & $0 \%$ & - & - & - & - \\
\hline Emergency ward & 1 & $1 \%$ & 0 & $0 \%$ & - & - & - & - \\
\hline (Missing) & 0 & $0 \%$ & 2 & $1 \%$ & - & - & - & - \\
\hline \multicolumn{9}{|c|}{ Specialist palliative care team involved in the patient's care before death } \\
\hline Yes & 80 & $82 \%$ & 117 & $66 \%$ & - & - & - & - \\
\hline No & 18 & $18 \%$ & 59 & $33 \%$ & - & - & - & - \\
\hline (Missing) & 0 & $0 \%$ & 2 & $1 \%$ & - & - & - & - \\
\hline \multicolumn{9}{|c|}{ Care of the patient supported by an individualised care plan } \\
\hline Yes & 60 & $61 \%$ & 63 & $35 \%$ & - & - & - & - \\
\hline No & 38 & $39 \%$ & 115 & $65 \%$ & - & - & - & - \\
\hline
\end{tabular}

incl., including; No, number; Prop, proportion. 


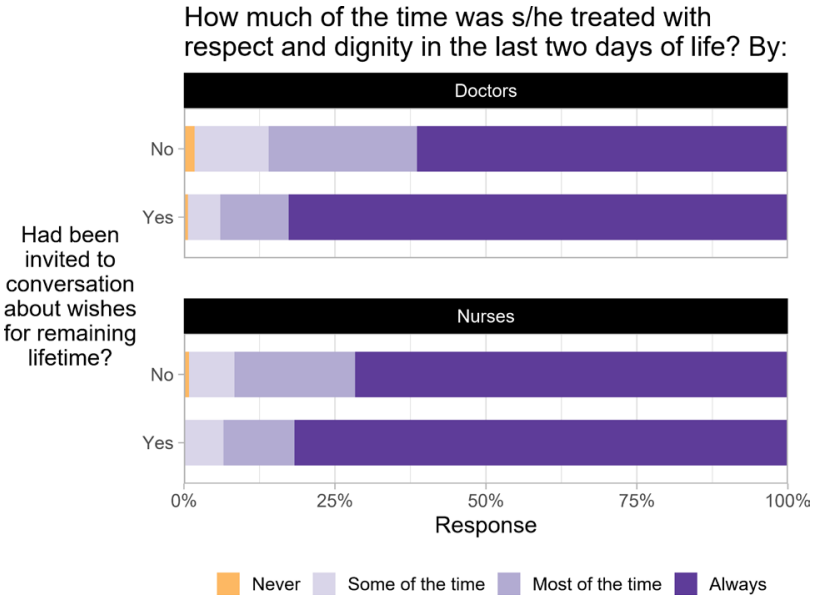

Figure 2 Association between having been invited to an advance care planning conversation and the participants' perception of how much of the time the patient was treated with respect and dignity $(n=274)$.

found for Q23 and Q30 for nurses ( $\mathrm{p}$ values 0.005 and 0.02 , respectively).

\section{DISCUSSION}

In this post-bereavement survey, $56 \%$ of the participants had been invited to an ACP conversation. The majority $(68 \%)$ of those who were not invited would have wanted such a conversation. Having been invited to an ACP conversation was associated with more favourable perceptions of the support and care given to both the patients and the participants themselves in the patient's final days.

In cancer care, the growing demand for shared decision-making has led to an increasing focus on goals-of-care discussions. ${ }^{18}$ During the last decade, ACP programmes have been implemented and studied as a means for these discussions, exploring patients' wishes and preferences for EoL care. ${ }^{719}$ In the present

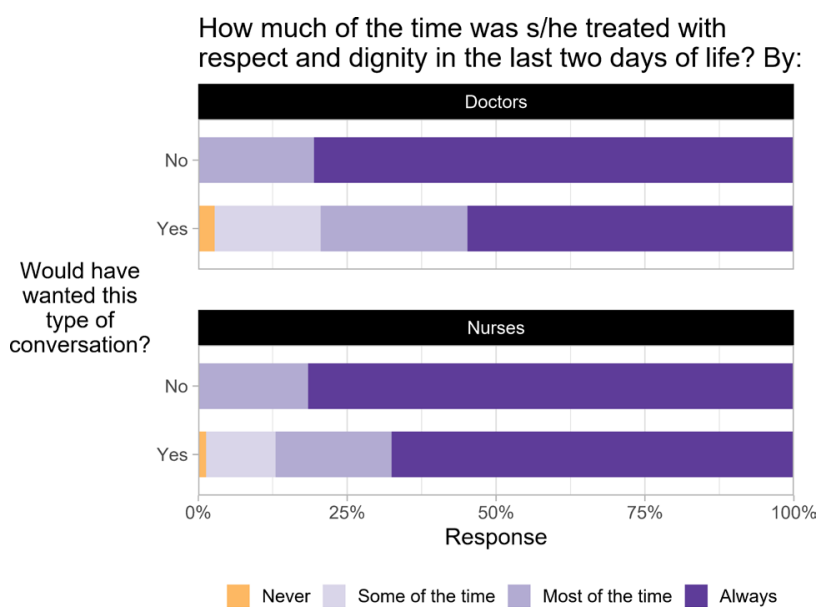

Figure 3 Association between having wanted to have an advance care planning conversation (but not offered one) and the participants' perception of how much of the time the patient was treated with respect and dignity $(n=115)$. study, we asked about an invitation to a conversation about wishes for the patient's remaining lifetime, but, based on the participants' responses about support and participation in EoL care discussions, we assume that the invitation normally led to a conversation.

The reported prevalence of ACP documentation in the USA varies between $18 \%$ and $70 \%$, presumably because of variations in the implementation of ACP programmes. ${ }^{20}$ As shown in Australia, the prevalence of ACP documentation is higher in regions where ACP is thoroughly implemented. ${ }^{21}$ In 2019 , ACP documentation in Australia was $41 \%$ across all sectors, and about $50 \%$ among people aged 65 or older. ${ }^{21}{ }^{22}$ However, counting documents does not give the full picture, as several conversations may be necessary before any documentation is produced. In a setting without an ACP programme, Fakhri et al discovered that only about $30 \%$ of patients with life-limiting diseases experienced EoL care discussions with their physician. ${ }^{23}$ Acknowledging the fact that neither Argentina nor Norway has any formal ACP programme in hospitals, it is encouraging that as many as $56 \%$ of the participants in the present study had been offered a conversation about wishes for the patient's remaining lifetime. However, a high proportion of the patients had been in contact with a specialist palliative care service, especially in Argentina (table 2). As goals-of-care discussions are often provided by specialist palliative care services, this may be part of the explanation why a surprisingly high percentage of ACP conversations were reported despite the lack of a systematic ACP approach.

Even though more than half of the participants in this study were invited to an ACP conversation, 44\% were not offered a conversation, which indicates an unmet need. This interpretation is supported by the fact that these participants perceived care and support less favourably than those offered a conversation. ACP conversations may contribute to a better understanding and acceptance of prognosis, and thus to a higher degree of consensus about treatment and care. ${ }^{72} 25$ Disagreement on values and preferences for life-sustaining treatment between seriously ill and hospitalised patients and their relatives may be considerable, and ignorance of this disparity may result in conflicts between family members and healthcare personnel. ${ }^{26}$ Johnson et al found that relatives of patients with cancer considered ACP as useful for themselves as for the patients, since the discussion contributed to reduced conflict and stress within the family. ${ }^{27}$ The process of ACP in itself can be therapeutic, and studies have shown that ACP leads to a reduction of stress, anxiety and depression among the bereaved. ${ }^{719} 28$

Thirty-two per cent of the relatives not offered an ACP conversation, expressed that they would not have wanted such a conversation. Their information needs may have been met in other ways. However, protective buffering or belief in positive thinking have been 
Table 3 Relationship between the two ACP questions and the primary outcomes and outcomes related to communication and support in the CODE International Survey $(n=276)$

\begin{tabular}{|c|c|c|c|c|c|c|c|c|}
\hline \multirow[b]{2}{*}{ Outcome/response variable* } & \multicolumn{4}{|c|}{$\begin{array}{l}\text { Q32a: Invited to conversation about } \\
\text { wishes for remaining lifetime? }(n=276)\end{array}$} & \multicolumn{4}{|c|}{$\begin{array}{l}\text { Q32b: Would have wanted this type of } \\
\text { conversation? }(n=117)\end{array}$} \\
\hline & No. & OR & $95 \% \mathrm{Cl}$ & $P$ value & No. & OR & $95 \% \mathrm{Cl}$ & P value \\
\hline Q16: Participant involved in decisions about care & 273 & 2.5 & 1.6 to 4.0 & $<0.001$ & 114 & 0.8 & 0.4 to 1.7 & 0.58 \\
\hline Q17: Participant involved in discussions about hydration & 250 & 3.7 & 2.1 to 6.4 & $<0.001$ & 107 & 0.9 & 0.4 to 2.3 & 0.89 \\
\hline Q20: Level of emotional support received & 272 & 2.8 & 1.8 to 4.5 & $<0.001$ & 116 & 0.3 & 0.1 to 0.6 & 0.001 \\
\hline Q21: Patient's spiritual needs met & 263 & 2.6 & 1.7 to 4.2 & $<0.001$ & 112 & 0.5 & 0.2 to 1.0 & 0.05 \\
\hline Q22: Participant's spiritual needs met & 264 & 2.7 & 1.7 to 4.3 & $<0.001$ & 113 & 0.4 & 0.2 to 0.8 & 0.01 \\
\hline Q23: Informed about impending death & 272 & 2.6 & 1.3 to 5.3 & 0.008 & 115 & 0.4 & 0.1 to 1.3 & 0.12 \\
\hline Q24: Informed about what to expect in the dying phase & 272 & 3.4 & 2.1 to 5.7 & $<0.001$ & 115 & 0.5 & 0.2 to 1.1 & 0.08 \\
\hline Q30: Patient treated with dignity and respect by doctors & 264 & 2.8 & 1.6 to 5.0 & $<0.001$ & 109 & 0.2 & 0.1 to 0.6 & 0.003 \\
\hline Q30: Patient treated with dignity and respect by nurses & 273 & 1.8 & 1.0 to 3.2 & 0.06 & 115 & 0.4 & 0.1 to 1.0 & 0.04 \\
\hline Q31: Participant adequately supported & 270 & 6.2 & 2.4 to 16.1 & $<0.001$ & 113 & 0.2 & 0.1 to 0.8 & 0.03 \\
\hline
\end{tabular}

The table shows ORs from ordinal mixed-effects regression models. Each row shows the results for the corresponding outcome variable. For item Q32a, an $O R>1$ indicates that the participants who were invited to an ACP conversation gave more positive responses on the outcome items in the questionnaire. For item Q32b, an OR $<1$ indicates that of the participants who were not invited, those who would have wanted such a conversation gave more negative responses on the outcome items; that is, they had unmet needs.

* See table 1 for complete description.

ACP, advance care planning; CODE, Care Of the Dying Evaluation; No, number of participants.

discovered as the most frequently reported barriers against ACP among relatives. ${ }^{29}$ Because of differences in preferences and needs among patients and relatives, mapping of individual needs and attitudes towards such conversations is essential for ACP recruitment. ${ }^{3031}$

The invitation to ACP conversations was positively associated with the relatives' perceptions about support and dignity and respect shown by doctors and nurses. We do not know whether this relates to the conversation per se or whether the offer of an ACP conversation is an indicator of a ward culture acknowledging the importance of communication and involvement. In Argentina, being informed about the patient's impending death was closely associated with having been offered an ACP conversation, as opposed to Norway, where the proportion of relatives being informed about impending death was the same for those offered an ACP conversation and those not. This was the only major difference detected between the countries. As Norway has a much longer tradition for palliative care than Argentina has, this finding strengthens the interpretation that ACP in this study may be seen as an indicator of a patient-centred and family-centred ward culture.

We believe that our results underline how important communication is for emotional and spiritual support and perceptions about care. Discordance between the patient and the oncologist about goals of care may negatively influence caregivers' satisfaction in EoL care. $^{32}$ Similarly, proxies who never attend medical visits report significantly worse medical care and care coordination than proxies who always attend such visits. ${ }^{33}$ In a longitudinal communication approach for patients with advanced lung cancer, patients and relatives described times of shock and coping deficits often related to insufficient communication and poor continuity of care. ${ }^{34}$ The feeling of safety, often highly valued by patients, may be increased by performing patient-centred ACP conversations in which patients and their relatives are seen, met and heard during the process of making achievable plans. ${ }^{1827}$

This study used a post-bereavement questionnaire to ask about ACP conversations. We have identified one similar survey. Mori et al asked bereaved relatives to patients with advanced cancer about EoL care and support, with the aim of evaluating the effects of in-advance EoL discussions on the quality of inpatient EoL care. ${ }^{35}$ Primary caregivers had higher ratings of overall EoL care and support and lower problem scores if an EoL discussion had taken place. In a longitudinal study, Garrido and Prigerson investigated modifiable predictors of caregivers' bereavement adjustment and found that encouraging ACP for patients with advanced cancer had a positive influence on the adjustment. ${ }^{36}$

\section{Strengths and limitations}

Although our study was limited to two countries, the countries differ in both culture and geography, and the study included a mix of hospitals in each country. We also had a moderately high response rate.

The CODE questionnaire focuses on the last 2 days of the patient's life and the immediate bereavement period, while the two additional ACP questions are not limited to the terminal phase. We cannot rule out that this distinction may have been overlooked by the respondents. On the other hand, piloting the questions did not reveal any comprehensibility problems. This also concerns the wording of the first ACP question, in which the expression 'your wishes' in English may be 
understood as singular or plural, while the expression in Norwegian and Spanish is exclusively plural.

Respondents who answered 'don't know' to the first question (Q32a) were excluded from the analysis. There is a risk that relatives who either had forgotten a conversation or who did not have a conversation have been excluded.

We do not have information about how and to which extent the ACP conversations were carried out. Another important limitation is that a high proportion of the patients were supported by a specialist palliative care team (both countries) or died in a palliative care unit (Norway). While specialist palliative care teams are available in almost all hospitals in Norway, this holds true only for a minority of Argentinian institutions, limiting the generalisability of the findings. ${ }^{3738}$

The study focused on expected deaths, so attempted resuscitation was an exclusion criterion. This may have excluded some patients who did not have ACP.

\section{Implications for practice}

Our findings show a positive association between the relatives being offered ACP and their perceptions of the care and support given. We do not know, however, whether this association is a direct effect or rather an indicator of a clinical culture and approach. Our findings nevertheless underline the importance of effective communication and involvement of patients and relatives in the planning of treatment and care.

There is an ongoing debate about which outcomes should be used to evaluate the effects of an ACP programme. ${ }^{39}$ In this study, there was an association between ACP being offered and outcomes such as respect and dignity, and emotional and spiritual support, which suggests that these outcomes may be considered for evaluation of ACP programmes.

\section{CONCLUSION}

Participants who had been invited to a conversation about wishes for the patient's remaining lifetime had more positive perceptions about care and support in the patient's final days of life, for the patient as well as for themselves. Most of the participants who were not offered an ACP conversation would have wanted it. This was true for both Argentina and Norway. Our findings suggest that a systematic approach to ACP and goals-of-care discussions may improve EoL care for patients with advanced cancer and support for their relatives.

\footnotetext{
Author affiliations

${ }^{1}$ Faculty of Medicine, Department of Clinical Medicine K1, University of Bergen, Bergen, Norway

${ }^{2}$ Specialist Palliative Care Team, Department of Anaesthesia and Surgical Services, Haukeland University Hospital, Bergen, Norway

${ }^{3}$ Centre for Clinical Research, Haukeland University Hospital, Bergen, Norway

${ }^{4}$ Regional Centre of Excellence for Palliative Care, Western Norway, Haukeland University Hospital, Bergen, Norway

${ }^{5}$ Pallium Latinoamérica, Buenos Aires, Argentina

${ }^{6}$ Instituto de Investigaciones Medicas Alfredo Lanari, University of Buenos Aires, Buenos Aires, Argentina
}

${ }^{7}$ Internal Medicine/Palliative Care Program, Hospital Privado Universitario de Córdoba, Córdoba, Argentina

${ }^{8}$ Department of Cancer Research and Molecular Medicine, Faculty of Medicine, Norwegian University of Science and Technology, Trondheim, Norway

${ }^{9}$ Palliative Medicine Unit, Cancer Clinic, St Olavs Hospital, Trondheim University Hospital, Trondheim, Norway

Twitter Nina Elisabeth Hjorth @neheida

Acknowledgements We thank the participants for providing the data for this study, and the study staff in the ten hospitals in Argentina and Norway for their skilled assistance.

Collaborators The ERANet-LAC CODE core scientific group: Dagny Faksvåg Haugen (project coordinator), Katrin Sigurdardottir, Marit Irene Tuen Hansen, Karl Ove Hufthammer (Norway), Wojciech Leppert, Katarzyna Wolszczak (Poland), Eduardo Garcia Yanneo (Uruguay), Vilma A Tripodoro, Gabriel Goldraij (Argentina), Martin Weber, Christina Gerlach (Germany), Lair Zambon, Juliana Nalin Passarini, Ivete Bredda Saad (Brazil), Catriona Mayland, Grace Ting, John Ellershaw (UK).

Contributors DFH, KS, VAT and NEH designed the study. AK, $\mathrm{DFH}, \mathrm{KS}, \mathrm{GG}$ and VAT were involved in the data collection. $\mathrm{KOH}, \mathrm{DFH}, \mathrm{KS}$ and $\mathrm{NEH}$ analysed the data. All authors contributed to data interpretation. $\mathrm{NEH}, \mathrm{KOH}$ and $\mathrm{DFH}$ drafted the article. All authors critically reviewed the article and approved the final version. $\mathrm{DFH}$ and $\mathrm{KOH}$ are guarantors for the study.

Funding The ERANet-LAC CODE project 'International Care Of the Dying Evaluation (CODE): quality of care for cancer patients as perceived by bereaved relatives' (reference ELAC2015/T07-0545, January 2017-January 2020) was funded through the 2nd Joint Call for Transnational Research and/or Innovation Projects within the ERANet-LAC Framework, co-funded by the European Commission's 7th Framework Programme (FP7), with the overall aim to improve the quality of care and quality of life of dying patients with cancer. We acknowledge funding from the Research Council of Norway (RCN, grant number 271051) and the Ministry for Science, Technology and Productive Innovation (MINCyT), Argentina.

Competing interests None declared.

Patient consent for publication Not applicable.

Ethics approval Approval was given by the Regional Committee for Medical and Health Research Ethics West (2017/640/REK vest), Norway, and Guía de Buenas Prácticas de Investigación Clínica en Seres Humanos, Ministerio de Salud de la Nación Argentina (Resolución 1480/2011).

Provenance and peer review Not commissioned; externally peer reviewed.

Data availability statement Data are available upon reasonable request.

Open access This is an open access article distributed in accordance with the Creative Commons Attribution Non Commercial (CC BY-NC 4.0) license, which permits others to distribute, remix, adapt, build upon this work noncommercially, and license their derivative works on different terms, provided the original work is properly cited, appropriate credit is given, any changes made indicated, and the use is noncommercial. See: http://creativecommons.org/licenses/by-nc/4. $0 /$.

\section{ORCID iDs}

Nina Elisabeth Hjorth http://orcid.org/0000-0003-1306-5439

Karl Ove Hufthammer http://orcid.org/0000-0003-3170-9496

Katrin Sigurdardottir http://orcid.org/0000-0001-8192-7470

Vilma Adriana Tripodoro http://orcid.org/0000-0003-2328-

6032

Dagny Faksvåg Haugen http://orcid.org/0000-0002-8592-4995 


\section{REFERENCES}

1 Lawler M, Banks I, Law K, et al. The European cancer patient's bill of rights, update and implementation 2016. ESMO Open 2017;1:e00127.

2 Shaw T, York S, White K, et al. Defining success factors to describe coordinated care in cancer. Transl Behav Med 2018;8:357-65.

3 Charles C, Gafni A, Whelan T. Shared decision-making in the medical encounter: what does it mean? (or it takes at least two to tango). Soc Sci Med 1997;44:681-92.

4 Barry MJ, Edgman-Levitan S. Shared decision making-pinnacle of patient-centered care. N Engl J Med 2012;366:780-1.

5 Austin CA, Mohottige D, Sudore RL, et al. Tools to promote shared decision making in serious illness: a systematic review. JAMA Intern Med 2015;175:1213-21.

6 Rietjens JAC, Sudore RL, Connolly M, et al. Definition and recommendations for advance care planning: an international consensus supported by the European association for palliative care. Lancet Oncol 2017;18:e543-51.

7 Thomas K, Lobo B, Detering K. Advance care planning in end of life care. 2nd edn. United Kingdom: Oxford University Press, 2018.

8 Lunder U, Červ B, Kodba-Čeh H. Impact of advance care planning on end-of-life management. Curr Opin Support Palliat Care 2017;11:293-8.

9 Norwegian cause of death registry: folkehelseinstituttet (the norwegian institute of public health), 2020. Available: https:// www.fhi.no/hn/helseregistre-og-registre/dodsarsaksregisteret/ [Accessed 07 Apr 2021].

10 Estadisticas Vitales. Informacion Basica Argentina - Ano 2018. 62. Argentina, diciembre de: Ministerio de Salud, 2019.

11 ERANet-LAC code project. Available: http://www.icode7.org/ icode7/homepage.html [Accessed 29 Sep 2021].

12 Mayland CR, Williams EMI, Addington-Hall J, et al. Assessing the quality of care for dying patients from the bereaved relatives' perspective: further validation of "evaluating care and health outcomes--for the dying". J Pain Symptom Manage 2014;47:687-96.

13 Mayland CR, Gerlach C, Sigurdardottir K, et al. Assessing quality of care for the dying from the bereaved relatives' perspective: using pre-testing survey methods across seven countries to develop an international outcome measure. Palliat Med 2019;33:357-68.

14 Haugen DF, Hufthammer KO, Gerlach C, et al. Good quality care for cancer patients dying in hospitals, but information needs unmet: bereaved relatives' survey within seven countries. Oncologist 2021;26:e1273-84.

15 R Core Team. R: a language and environment for statistical computing. [web page]. Vienna, Austria: R Foundation for Statistical Computing, 2020. https://www.R-project.org/ [Accessed

16 Christensen RH. Regression Models for Ordinal Data [Web page], 2019. Available: https://CRAN.R-project.org/package $=$ ordinal [Accessed 07 Apr 2021].

17 Rubinstein A, Zerbino MC, Cejas C, et al. Making universal health care effective in Argentina: a blueprint for reform. Health Syst Reform 2018;4:203-13.

18 Bakitas MA, El-Jawahri A, Farquhar M, et al. The TEAM approach to improving oncology outcomes by incorporating palliative care in practice. J Oncol Pract 2017;13:557-66.

19 Brinkman-Stoppelenburg A, Rietjens JAC, van der Heide A. The effects of advance care planning on end-of-life care: a systematic review. Palliat Med 2014;28:1000-25.

20 Bernacki RE, Block SD. Communication about serious illness care goals: a review and synthesis of best practices. JAMA Intern Med 2014;174:1994-2003.

21 Buck K, Detering KM, Sellars M, et al. Prevalence of advance care planning documentation in Australian health and residential aged care services. advance care planning Australia, Austin health, 2019. Available: https://www. advancecareplanning.org.au/docs/default-source/acpa-resourcelibrary/acpa-publications/report-national-acd-prevalence-study2019. pdf? Status $=$ Temp\&sfvrsn $=83 \mathrm{~d} 2$ eb3c_ 4 [Accessed 07 Apr 2021].

22 Detering KM, Buck K, Ruseckaite R, et al. Prevalence and correlates of advance care directives among older australians accessing health and residential aged care services: multicentre audit study. BMJ Open 2019;9:e025255.

23 Fakhri S, Engelberg RA, Downey L, et al. Factors affecting patients' preferences for and actual discussions about end-oflife care. J Pain Symptom Manage 2016;52:386-94.

24 Overbeek A, Korfage IJ, Hammes BJ, et al. Experiences with and outcomes of advance care planning in bereaved relatives of frail older patients: a mixed methods study. Age Ageing 2019;48:299-306.

25 Loh KP, Mohile SG, Lund JL, et al. Beliefs about advanced cancer curability in older patients, their caregivers, and oncologists. Oncologist 2019;24:e292-302.

26 Abdul-Razzak A, Heyland DK, Simon J, et al. Patient-family agreement on values and preferences for life-sustaining treatment: results of a multicentre observational study. BMJ Support Palliat Care 2019;9:e20.

27 Johnson SB, Butow PN, Kerridge I, et al. What do patients with cancer and their families value most at the end of life? A critical analysis of advance care planning. Int J Palliat Nurs 2017;23:596-604.

28 Detering KM, Hancock AD, Reade MC, et al. The impact of advance care planning on end of life care in elderly patients: randomised controlled trial. BMJ 2010;340:c1345.

29 Nagelschmidt K, Leppin N, Seifart C, et al. Systematic mixedmethod review of barriers to end-of-life communication in the family context. BMJ Support Palliat Care 2021;11:253-63.

30 Andreassen P, Neergaard MA, Brogaard T, et al. The diverse impact of advance care planning: a long-term follow-up study on patients' and relatives' experiences. BMJ Support Palliat Care 2017;7:335-40.

31 Spelten ER, Geerse O, van Vuuren J, et al. Factors influencing the engagement of cancer patients with advance care planning: a scoping review. Eur J Cancer Care 2019;28:e13091.

32 Douglas SL, Daly BJ, Meropol NJ, et al. Patient-physician discordance in goals of care for patients with advanced cancer. Curr Oncol 2019;26:370-9.

33 Roydhouse JK, Gutman R, Keating NL, et al. The association of proxy care engagement with proxy reports of patient experience and quality of life. Health Serv Res 2018;53:3809-24.

34 Villalobos M, Coulibaly K, Krug K, et al. A longitudinal communication approach in advanced lung cancer: a qualitative study of patients', relatives' and staff's perspectives. Eur J Cancer Care 2018;27:e12794.

35 Mori M, Ellison D, Ashikaga T, et al. In-advance end-of-life discussions and the quality of inpatient end-of-life care: a pilot study in bereaved primary caregivers of advanced cancer patients. Support Care Cancer 2013;21:629-36.

36 Garrido MM, Prigerson HG. The end-of-life experience: modifiable predictors of caregivers' bereavement adjustment. Cancer 2014;120:918-25.

37 Centeno C, Lynch T, Garralda E, et al. Coverage and development of specialist palliative care services across the world health organization european region (2005-2012): results from a european association for palliative care task force survey of 53 countries. Palliat Med 2016;30:351-62.

38 Soto-Perez-de-Celis E, Chavarri-Guerra Y, Pastrana T, et al. End-of-life care in latin america. J Glob Oncol 2017;3:261-70.

39 Sudore RL, Heyland DK, Lum HD, et al. Outcomes that define successful advance care planning: a Delphi panel consensus. $J$ Pain Symptom Manage 2018;55:245-55. 